\title{
Epstein Barr Virus-associated Pediatric Neoplasms
}

\author{
Mozhgan Hashemieh ${ }^{1}$ and Fariba Shirvani ${ }^{2,{ }^{*}}$ \\ ${ }^{1}$ Imam Hossein Medical Center, Shahid Beheshti University of Medical Sciences, Tehran, Iran \\ ${ }^{2}$ Pediatric Infections Research Center, Research Institute for Children's Health, Shahid Beheshti University of Medical Sciences, Tehran, Iran \\ "Corresponding author: Pediatric Infections Research Center, Research Institute for Children Health, Shahid Beheshti University of Medical Sciences, Tehran, Iran. Email: \\ shirvanifariba@rocketmail.com
}

Received 2019 May 29; Revised 2020 January 22; Accepted 2020 January 26.

\begin{abstract}
More than $90 \%$ of the world population experience the infection by Epstein-Barr virus (EBV), this virus has the potential to survive in B cells for the entire life period of infected individuals. However, if the balance between host and virus is disturbed, silent EBV infection could change to neoplasms. Socioeconomic factors affect exposure to EBV so the age of primary infection varies worldwide. In underdeveloped population infection occurs at lower age and EBV infection remains subclinical in high number of patients. Different neoplasms associated with EBV infection are EBV-positive Hodgkin lymphoma (HL), EBV-associated Burkitt lymphoma, diffuse large B-cell lymphoma, post-transplant lymphoproliferative disorders (PTLD), smooth muscle tumor and nasopharyngeal carcinoma. This review article presents detail information about pathogenesis, clinical presentation and treatment of pediatric patients with these disorders.
\end{abstract}

Keywords: EBV, Children, Neoplasm

\section{Context}

Epstein Barr virus (EBV) is a double-stranded DNA virus that belongs to the Herpesviridae family. The virus has infected more than $90 \%$ of the world's population and is characterized by a specific affinity to B cells. It invades epithelial cells, natural killer cells, and T cells. Like all herpes viruses, EBV remains in the host during life, but most virus carriers are asymptomatic. Primary EBV infection is asymptomatic in childhood but infectious mononucleosis might occur as a self- limiting illness in adolescents and children. The EBV infection can become latent and may be associated with various neoplasms, usually lymphoid and non-lymphoid childhood cancers in rare cases. This virus may cause many lymphoproliferative disorders (LPDs) of B cell types, including Hodgkin's lymphoma (classic type), diffuse large B cell lymphoma (DLBC), Burkitt lymphoma, LPD associated with immune deficiency, and LPDs occurring secondary to transplant and human immunodeficiency virus infection. Also, this virus may have an important role in a group of peripheral lymphomas of T-cell origin, including angioimmunoblastic T-cell lymphomas, nasal natural killer/T-cell lymphomas (extranodal), smooth muscle tumor, and nasopharyngeal carcinoma (NPC). Hemophagocytic lymphohistiocytosis (HLH) is a clinicopathologic syndrome with dysregulation of the immune system and hypercytokinemia. Most neoplasms associated with EBV infection respond poorly to intensive chemotherapy protocols; therefore, in these cancers, it is necessary to use regimens directed at viral targets. In this review article, we discuss childhood malignancies concerning EBV infection, clinical manifestations, pathological characteristics, and treatment modalities of these disorders in children.

\section{Evidence Acquisition}

Based on our search strategy, we conducted a thorough literature review and selected relevant articles. We performed a Google Scholar and PubMed literature review. We used PubMed MeSH terms, including Epstein-Barr virus, human herpesvirus 4, IM, HHV-4, glandular fever, mononucleosis, lymphoma, lymphoproliferative disorder/cancer, lymph node cancer, infectious mononucleosis, children, neoplasm, Hodgkin lymphoma, immunodeficiency, Burkitt lymphoma, diffuse large B cell lymphoma, post-transplant lymphoproliferative disorders, smooth muscle tumor, nasopharyngeal carcinoma, hemophagocytic lymphohistiocytosis syndrome, and Anti-Epstein-Bar virus drugs . After abstract extraction, we screened the abstracts for relevance to the main idea of this review. Our priority was to select original articles, systematic reviews, and meta-analyses. We cited case reports for special points 
and uncommon findings. The other priority was to focus on articles concerning immunocompromised cases in young children rather than adults. As we were to assess a greater number of relevant articles, numerous relevant references were refined by the PubMed search presented with the "similar articles" tab. A pool of 74 research articles including 23 review articles, one meta-analysis, one case report, and 44 research articles published from 1997 to 2019 was used for data gathering. The results and perspectives on the main concept are presented.

\section{Results}

\subsection{Principles}

Epstein-Barr virus (EBV) was isolated from Burkitt Lymphoma cells nearly 50 years ago (1964) (1). It is a doublestranded DNA virus from the Herpesviridae family with a proven association with cancer. This virus has a definite tropism for B cells but can infect T cells, natural killer cells, and epithelial cells. More than $90 \%$ of the population worldwide carry the virus (2). This virus may establish a silent lifelong infection (3) and the age of primary infection varies in different societies depending on socioeconomic factors. Data indicate that a poor socioeconomic background is associated with a higher antibody level at lower ages, which has been attributed to a higher chance of acquiring the disease at a lower age (4). Primary EBV disease is asymptomatic in childhood but infectious mononucleosis (IM) syndrome might occur as a self-limiting illness in an adolescent with fever, malaise, splenomegaly, pharyngitis, and atypical lymphocytosis (5). During the IM phase, a lymphoid reactivation may occur, which is selfresolved by $T$ cell reaction against infected $B$ cell proliferation. The propagation of virion components including viral DNA and proteins may occur in the lytic phase but the latent phase is accompanied by the expression of six nuclear antigens (EBNA1, 2, 3A, 3B, 3C, and LP), two non-coding small RNA (EBER 1 and 2), and three latent membrane proteins (LMP1, 2A, and 2B) (6). Epstein-Barr virus replication in the lytic phase is followed by a latent (antigennegative) phase accompanied by the infection of memory B cells (7). The Epstein-Barr virus is found to have a potent $B$ cell growth transforming agent by which it can promote lymphomagenesis through oncogenic mechanisms (8). This oncogenic capacity is related to latency and gene expression mechanisms of the virus. There are three latency types. Different antigens are expressed in each latency. In latency 1, EBER and EBNA1 are expressed. In latency 2, LMP1 and 2 are expressed and in latency 3, EBER, all six EBNAs, and two LMPs are expressed. Several EBV-positive tumor types have specific gene expressions that may not exactly fall in these three latency categories. Epstein-Barr virus may be responsible for many B cell lymphoproliferative disorders, such as Hodgkin's lymphoma (classic type), LPDs associated with immunodeficiency virus, posttransplant and immune-deficiency-associated LPDs, and Burkitt lymphoma. Also, this virus may have an association with a group of T-cell lymphomas of peripheral origin, such as nasal natural killer/extranodal T-cell lymphomas, angioimmunoblastic T-cell lymphomas, gastric adenocarcinoma, and smooth muscle tumors. The Epstein-Barr virus is associated with many carcinomas. The detection of EBNA1 in tumoral tissue is an interesting criterion to consider EBV as the responsible virus (9).

\subsection{Epstein-Barr Virus-associated Lymphoid Malignancies}

Many of the lymphoid malignancies are caused by latent EBV infection. The Epstein-Barr virus is responsible for $20 \%$ of Burkitt lymphoma (BL) cases in immunocompetent persons in developing countries. Approximately all cases of African type BL, 50\% of Hodgkin lymphoma cases, and certain types of large B cell lymphoma (diffuse type) and T cell lymphoma are caused by EBV. Lymphoproliferative disorders associated with EBV can be classified into two groups; the first group originates from $\mathrm{B}$ cells and the second one has an association with $\mathrm{T}$ or natural killer (T/NK) cells. Epstein-Barr virus-associated LPDs have four subtypes including classical Hodgkin lymphoma, Burkitt lymphoma, lymphoproliferative disorders secondary to transplantation, and LPDs associated with HIV. The HIV accompanied LPDs can be classified into four groups: primary CNS lymphoma, diffuse large B cell lymphoma (immunoblastic), Human Herpesvirus 8 (HHV 8), and plasmablastic lymphoma. The NK and T cell lymphoproliferative disorders associated with EBV have three categories, peripheral (unspecified) T cell lymphoma, T cell lymphoma (angioimmunoblastic type), and nasal T/NK cell lymphoma (extranodal type) (10).

\subsection{Epstein-Barr Virus-associated Hodgkin Lymphoma}

Childhood Hodgkin lymphoma represents approximately $10 \%$ of all diagnosed Hodgkin lymphoma cases. Moreover, 30\% - 50\% of Hodgkin lymphoma cases are associated with EBV (EBV-positive Hodgkin lymphoma). This type of Hodgkin lymphoma is more common as a mixed cellularity subtype, and often occurs in children and older adults ( $>45$ years) (11).

\subsection{Histopathology of Hodgkin Lymphoma}

Two pathological entities are found in Hodgkin lymphoma: Nodular lymphocyte predominant (NLPHL) and 
classical Hodgkin lymphoma (CHL). Nodular lymphocytepredominant comprising $5 \%$ of Hodgkin lymphoma cases may have a germinal center genotype and typically is not EBV-positive. Classical Hodgkin lymphoma has a postgerminal center genotype and is divided into four subtypes: mixed cellularity (MCHL), nodular sclerosis (NSHL), lymphocyte depleted (LDHL), and lymphocyte rich (LRHL). The most common subtypes are NSHL and MCHL, in sequence. Each of LDHL and LRHL comprises less than 5\% of all CHL cases. In most cases of mixed cellularity and lymphocyte depleted subtypes, EBV can be detected in almost $40 \%$ of Hodgkin Reed-Sternberg (HRS) cells of classical Hodgkin lymphoma (11). childhood Hodgkin lymphoma shows a typically higher prevalence of male gender and in 30-35\% of cases are mixed cellularity subtypes. Epstein-Barr virus has been detected in 15\% - 20\% of NSHL cases and has never been found in LRHL; these two subtypes have a better prognosis. Therefore, in the classical type of Hodgkin lymphoma, EBV infection has a close relationship with prognosis. In HL, blood EBV-DNA is cell-free. Thus, cell-free EBV-DNA can show the tumor burden and in [U+FB02] ammation or immunity cell destruction. As a result, cell-free DNA may be a biomarker for prognosis or disease severity assessment (12).

\subsection{Epstein-Barr Virus-Positive Hodgkin Lymphoma in Immun- odeficient Patients}

The incidence of CHL is 10-fold higher in HIV-infected people than in the general population, and the majority of these cases are EBV-positive subtypes (8). Although retroviral therapy concomitant with chemotherapy often may result in complete remission, the rate of opportunistic infections increases in these patients (13).

\subsection{Influence of EBV on Prognosis of Hodgkin Lymphoma}

The results of studies about the effect of EBV on the prognosis of Hodgkin lymphoma are conflicting. In a study on the Swedish adult population, patients with EBVpositive Hodgkin lymphoma had more symptoms and lower survival than EBV-negative Hodgkin lymphoma patients (14). Although EBV-positive Hodgkin lymphoma in young adults is associated with improved disease-free survival, this condition does not affect overall survival (15). These conflicts may be due to the age of participants in those studies. In a study by Chabay et al. in South America, EBV had a role in the pathogenesis of mixed cellularity subtype, but in their pediatric series, EBV status had no effect on the prognosis of Hodgkin lymphoma (16).

The treatment protocol is identical in both EBVpositive and EBV-negative Hodgkin lymphoma cases and results in long-term remission in the majority of cases, but relapsed EBV-positive Hodgkin lymphoma patients have a poor prognosis (17).

\subsection{Burkitt Lymphoma}

Burkitt lymphoma (BL) is more frequent in men than in women and is mostly diagnosed in children. Burkitt lymphoma is an aggressive B cell origin malignancy that can be classified into three forms with different geographic distributions, including sporadic BL, endemic BL, and HIV-associated BL. The hallmark of all BL tumors is the translocation between one of the immunoglobulins (Ig) light or heavy chain loci and the MYC gene. Sporadic BL is rarely associated with EBV. Endemic BL in more than 95\% of all cases is associated with EBV and more prevalent in malaria hyperendemic areas such as Africa and other parts of the world (18). Burkitt lymphoma has one of the highest cell proliferation rates among various neoplasms (doubling time of tumor is 24 to $48 \mathrm{~h}$ ) (19). Sporadic BL often involves the abdomen, but manifestations of endemic BL commonly occur in jaws and kidneys although they may be seen in the abdomen, ovaries, facial bones, and other extranodal sites (18). Moreover, HIV carriers have a 10 to 100fold higher incidence of BL than normal population (20). The main histopathologic feature of this neoplasm is the mass of small non-cleaved malignant B cells, which are interfused with non-neoplastic macrophages that may produce a sky with star appearance (18).

The Ki67 antigen is positive in almost $100 \%$ of the cells. Another characteristic of BL is the immunoglobulin gene rearrangement. Also, the transcripts of EBV-encoded small RNA (EBER)-positive cells are detected by the in-situ hybridization method in EBV-associated cases. Treatment of BL has the risk of tumor lysis syndrome due to the high doubling time of tumor cells. However, urate oxidase (Rasburicase) usage can reduce these complications. Sporadic BL outcome, especially in high-income countries, is much better than that of other types of BL (21). Today, imaging modalities play a role in the prognostic and therapeutic assessment of Burkitt lymphoma and PET-CT can demonstrate hypermetabolic activity in anatomic locations of the tumor (22).

\subsection{Diffuse Large B Cell Lymphoma}

This type of lymphoma rarely manifests in children < 4 years of age and its incidence may increase from childhood towards the second decade of life (23). Diffuse large B cell lymphoma is a variant of high-grade non-Hodgkin lymphomas and has two subtypes: activated B-cell like (ABC) diffuse large $B$ cell lymphoma (DLBCL) and germinal center B-cell like (GCB) DLBCL. Approximately $10 \%$ of the DLBCL cases are EBV-positive. The EBV-positive DLBCL cases have 
a higher extranodal involvement rate, more refractory disease, and a more aggressive clinical course (8). In DLBCL, tumor cells often express pan B cell markers (CD 20, CD 79a) and the majority of these cells are CD30-positive but lack CD15 expression (9). This type of non-Hodgkin lymphoma may often involve extranodal sites including the skin, tonsils, stomach, and lungs. Unfavorable prognostic factors include a high international prognostic index, activated $\mathrm{B}$ cell phenotype, and older age (24). A relatively rare subset of EBV-positive DLBCL manifests in the presence of chronic inflammation. This type of malignancy occurs in body cavities, especially in pyothorax-associated lymphoma (PAL). A history of chronic pleuritis or chronic pyothorax is associated with PAL (25). Other EBV-positive DLBCLs associated with chronic inflammation occur in patients with bone and joint metallic implants, chronic leg ulcers, and chronic osteomyelitis (26). Another subset of DLBCL occurs in HIV-positive patients. Recent studies have shown that overall, $30 \%-35 \%$ of these tumors are EBV-positive (8)

\subsection{Post-Transplant Lymphoproliferative Disorder}

Recipients younger than 18 years of age at organ transplantation have a two to four-time higher risk of post-transplant lymphoproliferative disorder (PTLD) development than adult transplant patients (27). Among solid organ transplant recipients, the risk of EBV-positive B lymphoproliferative disorder (B-LPD) increases due to long-term immunosuppression. In the first-year posttransplant, LPD has an acute course and patients may have an increased risk of post-transplant lymphoma, especially DLBCL, during the lifetime, which is proportional to the immune suppression degree (28). The majority of posttransplant lymphomas are aggressive and EBV-positive.

The PTLD incidence ranges from $0.5 \%$ to $30 \%$ and varies greatly depending on the transplanted organ, the status of EBV in the transplant donor and recipient, and the drug regimen for immune suppression. These disorders are often B cell neoplasms. Also, concurrent cytomegalovirus infection, receiving T cell-depleted marrow, and intensity of immunosuppression have critical roles in the pathogenesis of PTLD. This disorder commonly occurs in the combined liver-kidney transplant, followed by cardiac, lung, and kidney transplants, in sequence. Posttransplant lymphoproliferative disorders that manifest in bone marrow transplant recipients are usually of donor origin, but in solid organ transplants, they are usually of recipient origin. Viral load is higher when whole blood is used in contrast to serum in PCR assessment although a biopsy should be done to confirm the virus presence (29). The main component of PTLD treatment is the reduction of immune suppression. Other therapies include antiviral agents, interferons, monoclonal antibodies, cell therapy, and chemotherapy (30). The Epstein-Barr virus is approximately $100 \%$ associated with Hodgkin lymphomaassociated PTLD. The EBV-negative PTLDs constitute approximately $20 \%$ of all cases and often occur in the late phase (31).

\subsection{Smooth Muscle Tumor}

Smooth muscle tumor (SMT) is an uncommon tumor that may occur in immunodeficient individuals. It may also occur in patients with human immunodeficiency virus infection and in post-transplant conditions; it may also be congenital. It occurs in $60 \%$ of post-transplant patients and is the second most common tumor in AIDS patients. The association between EBV infection and immunodeficiency was first described in 1970 and its clear association was confirmed in 1995 (32). Besides, SMT may occur in primary immunodeficiency conditions such as a mutation in ATM, ADA, IL2RG, ZAP70, CARMIL2, and GATA2 deficiency. Patients with EBV-positive SMT should be evaluated for immunodeficiency. The pathogenesis of this tumor is not well understood (33).

It is known that EBV-RNA in-situ hybridization can distinguish EBV-associated SMT from leiomyomas of deep soft tissue. This identification is essential to correct recognition of this category of SMTs because they may show unpredictable behavior (34).

Two different types of EBV are found in human infections. Type 2 is responsible for transformation in immunocompromised patients (35). Generally, the latency type 3 pattern is expressed and the cells are positive for EBNA 2, 3, and LMP1 (36). Epstein-Barr virus serology is positive in the majority of these patients but it has no direct relationship with the burden of disease or recurrence (37). Moreover, EBV is transmitted to the mucous membrane through the saliva via CD21 receptors on B cells. Therefore, SMT cells may express CD21 on their surfaces (38), except posttransplant subtype (PT-SMT) cells. The myc overexpression in some EBV-SMT tumors occurs and the result is cellular hyperplasia (39). The proliferation of SMT cells is promoted by the activation of the mTOR pathway and triggered by LMP2, an EBV latency membrane protein (40). Multifocal clones of SMT analysis show EBV insertion and their occurrence in an individual patient is caused by independent primary lesions rather than a metastasis (41).

The clinical features of post-transplant SMT (PT-SMT), congenital immunodeficiency SMT (CI-SMT), and HIV-SMT are pain and organ dysfunction depending on the site and size of tumors. Their sizes can be less than 5 to $21 \mathrm{~cm}$ in diameter. This tumor type tends to occur either in one place or in multiple sites (42). In HIV-SMT, the most commonly reported cases occur in CNS, GI, skin, larynx, pharynx, liver, 
and adrenal glands (43), but in PT-SMT cases, the most common involvement site is the liver although lungs, larynx, pharynx, gut, spleen, kidneys, brain, and rarely adrenal glands and iris can be affected (44). The most probable differential diagnosis of this tumor is non-Hodgkin lymphoma in the background of immune deficiency such as PTLD (45).

\subsection{Nasopharyngeal Carcinoma}

The association between nasopharyngeal carcinoma (NPC) and EBV was previously established in 1973. Nasopharyngeal carcinoma has been classified by the World Health Organization (WHO) into two main histologic types, keratinizing squamous cell carcinoma (type I) and non-keratinizing squamous cell carcinoma (types II and III), based on the tumor cells' appearance under the light microscope. The non-keratinizing type is further subdivided into differentiated non-keratinizing carcinoma (type II) and undifferentiated carcinoma (type III) that are predominantly EBV-positive (46). Similar features are described in thymus, tonsils, stomach, lungs, and skin, named as undifferentiated carcinoma of nasopharyngeal type or lymphoepitheliomas-like carcinoma that may be EBV-positive in the stomach (47). No human tumor is consistently associated with EBV as non-keratinizing nasopharyngeal carcinoma. Although EBV can persist as a latent infection in B memory cells, the presence of this virus in nasopharyngeal tissue as a latent virus is not postulated; thus, lytic expression plays an important role in its oncogenesis. The Epstein-Barr virus is not found in normal epithelial cells, even in adjacent tissues to EBV-positive NPC (48). Moreover, it is postulated that in-situ carcinomas are probable precursors of NPC lesions. In addition, LMP1 (EBV latent membrane protein) is expressed in all primary NPC tissues. This protein induces a specific effect on malignant phenotypes including cell cycle (Cyclin D1, Op18, EGFR, p53, STAT3), reprogramming of metabolism (hexokinase 2), angiogenesis (vascular endothelial growth factor), Epithelial-Mesenchymal Transmission (EMT), metastasis and invasion (C-X-C motif chemokine receptor 4), and apoptosis (49). Other latent genes are EBNA1, EBNA2, LMP2, BART2, and miR-BART (50). More than $60 \%$ of tumor suppressor genes are methylated. This hypermethylation may occur through the activation of DNA methyltransferase1 in cells and mitochondria by LMP1. This epigenetic mechanism plays an important role in the early stage of NPC (51). The lytic phase of EBV infection in contrast to the latent phase in other tumors is responsible for the oncogenesis property. In patients with NPC, high levels of lytic phase proteins BALF1/BCRF1/BHRF1 are expressed and DNA viral load and Viral Capsid Antibody (VCA) are increased (52). Nasopharyngeal carcinoma is located in the lateral or posterior wall of the nasopharynx around the Rosenmuller fossa. This cancer may remain asymptomatic with a few primary symptoms for a long time, making its early diagnosis difficult. It tends to spread to the parapharyngeal space. Metastasis to lymph nodes occurs in 70\% - 90\% of cases and it is unilateral in $50 \%$ of cases (53). The age range is 10 - 59 years and it is not prevalent in childhood. The most presenting symptoms are painless neck mass in $60 \%$, nasal obstruction in $50 \%$, headache in $54 \%$, hearing loss in $32 \%$, epistaxis in $10 \%$, trismus in $4 \%$, loss of vision and diplopia/squint each in $2 \%$ (54).

\subsection{Hemophagocytic Lymphohistiocytosis Syndrome}

It is a clinicopathologic syndrome with the dysregulation of the immune system and hypercytokinemia clinically characterized by splenomegaly, fever, cytopenia, hepatomegaly, coagulopathy, and central nervous system disturbances that may be accompanied by moderate pleocytosis and spinal fluid hyperproteinemia. The Histiocyte Society presented five diagnostic criteria for HLH in 2004, including (1) fever, (2) cytopenias affecting at least two of three lineages in the peripheral blood, (3) splenomegaly, (4) hemophagocytosis in the bone marrow, spleen, or lymph nodes, and (5) hypertriglyceridemia and/or hypofibrinogenemia. Moreover, three additional criteria have been described, including (6) hyperferritinemia, (7) low or absent NK-cell activity, and (8) high levels of soluble interleukin 2 receptor. Five of the eight criteria should be present to fulfill the condition, but patients with the presence of molecular diagnosis compatible with HLH necessarily do not need to fulfill the diagnostic criteria (55). Without treatment, death may occur due to multiorgan failure (56). The Epstein-Barr virus is highly associated with HLH in Asia due to unknown reasons (57). Primary HLH may occur in patients with genetic causes of HLH or positive family history (58). Differentiation between primary EBV infection and HLH is very difficult (59). The confirmatory diagnostic test for the identification of EBV-HLH is the determination of EBV genomic DNA in serum, lymph node, and bone marrow by PCR and in-situ hybridization (60).

Bone marrow smears in EBV-HLH show the phagocytosis of hematologic elements such as RBC and platelets and EBV-Encoded RNA(EBER)-positive staining of the bone marrow reveals EBV extensively infected lymphocytes presented in the background (61).

\subsection{Treatment of EBV-associated Neoplasms}

Epstein-Barr virus-associated neoplasms often respond poorly to intensive chemotherapy protocols; therefore, in these malignancies, the use of regimens directed at 
viral targets is necessary (62). These treatments include immune therapy approaches, interferons, and small molecule targeting aspects of virus biology (63).

\subsection{Antivirals}

Many antiviral agents have some anti-EBV activity. Ganciclovir and acyclovir are not the drugs of choice in EBVassociated lymphoid disorders. These two drugs have activities against lytic EBV disease. In the lytic form of EBV, acyclovir and ganciclovir are converted by the viral thymidine kinase gene into their active and toxic forms. The incorporation of these toxic metabolites into DNA leads to premature apoptosis. One of the modalities for solving this problem is the co-administration of these antiviral agents with 5-azacitidine as a demethylating compound, which induces the gene of the lytic cycle (64). Feng et al. showed that in severe combined immune immunodeficient (SCID) mice, the addition of doxorubicin or gemcitabine to ganciclovir had more inhibitory effects on EBVdriven lymphoproliferative disease than chemotherapy alone (65).

Foscarnet is another antiviral drug that its mechanism of action is independent of the presence of viral thymidine kinase and targets viral DNA polymerase. Oertel and Riess showed complete remission with foscarnet in patients with EBV-associated lymphoproliferative disorders (66). Cidofovir is a potent inhibitor of EBV replication in vitro and its action is directed against EBV DNA polymerase.

Nasopharyngeal xenografts are significantly affected by the antitumor influence of this drug (67). The coadministration of cidofovir and rituximab (anti-CD20 monoclonal antibody) can result in complete remission in CD20-expressing post-transplant lymphoproliferative disorders (68). Zidovudine is an antiretroviral agent for the treatment of HIV. The administration of zidovudine with interferon could induce in vitro apoptosis in EBV-positive lymphoma cells from a patient with AIDS (69). Another pharmacologic agent is hydroxyurea that affects the eradication of extrachromosomal DNA elements. The action mechanism of this drug is the elimination of EBV episomes in EBV-positive Burkitt lymphoma cell lines (63).

\subsection{Immunotherapy}

One of the immunotherapy methods in the treatment of EBV-positive non-Hodgkin lymphoma is the adoptive transfer of EBV-specific cytotoxic T lymphocytes (CTLs)(69). The CTLs can be infused directly from the donor into the patient or can be infused after in vitro expansion to reestablish immune system competence. The EBV-specific CTLs generation from seropositive healthy donors may take 8 to 12 weeks. This method may eradicate lymphoproliferative disorders after allogeneic hematopoietic stem cell transplantation. In patients with EBV-positive lymphoproliferative disorders who are recipients of solid organ transplants, $\mathrm{T}$ cells from the donor have little benefits because the tumor always occurs in recipient B cells (70). For non-transplant EBV-related neoplasms, there is limited experience of EBV-specific CTLs (30). Lucas et al. demonstrated the role of allogeneic EBV-specific CTLs in the treatment of recurrent, refractory EBV-positive Hodgkin disease (71). The most important complications of adoptive immune therapy include tumor resistance and graft versus host disease (GVHD). Etiologically, tumor resistance is probably due to EBV epitope mutations that are recognized by CTLs or other ways such as the production of cytokines including interleukin 10 (IL-10) (72). There is ongoing research to produce EBV vaccines aiming to protect against initial infection or boosting immunity for tumors associated with EBV infection. Clinical trials should be designed to determine if an EBV vaccine can reduce the rate of posttransplant lymphoproliferative disorders (73).

\subsection{Monoclonal Antibodies}

The availability of rituximab offers an opportunity for the treatment of EBV-associated B cell LPDs. The rate of response to rituximab varies between $70 \%$ and $100 \%$ (63). Also, in post-transplant lymphoma, IL-6 acts as a growth factor; thus, anti-IL-6 monoclonal antibodies are tried (72). In patients with high-risk or clinically aggressive lymphomas, additional therapy is necessary. A combination of rituximab and chemotherapy consisting of cyclophosphamide, doxorubicin, vincristine, and prednisolone (CHOP) has shown to increase survival (74).

\section{Conclusions}

Epstein-Barr virus has been found in many tumors with epithelial cells, B, T, and Natural Killer (NK) origin. A strong correlation exists between primary EBV infections and various pediatric subtypes of lymphoma such as Hodgkin disease, Burkitt lymphoma, diffuse large B cell lymphoma, and rarely smooth muscle tumor and nasopharyngeal carcinoma. Also, the high prevalence of EBV infection in early childhood may result in the development of hemophagocytic lymphohistiocytosis. Detection of EBV may be helpful for prognostic, diagnostic, and therapeutic purposes.

Among promising treatment modalities, especially in setting of PTLD, which occurs in allogeneic stem cell transplantation, is trying to restore the host's immune response by EBV-specific cytotoxic T cells infusion. Further studies should be implemented to determine the role of these cells 
and the efficacy of EBV vaccines to reduce the rate of infectious mononucleosis or post-transplant lymphoproliferative disorders.

\section{Footnotes}

Authors' Contribution: Mozhgan Hashemieh and Fariba Shirvani equally contributed to the writing of different parts of the article and its revision.

Conflict of Interests: There is no conflict of interest with the subject matter of the present study.

Funding/Support: There is no funding/support for this article.

\section{References}

1. Epstein MA, Achong BG, Barr YM. Virus particles in cultured lymphoblasts from Burkitt's lymphoma. Lancet. 1964;1(7335):702-3. doi: 10.1016/s0140-6736(64)91524-7. [PubMed:14107961].

2. Ok CY, Li L, Young KH. EBV-driven B-cell lymphoproliferative disorders: from biology, classification and differential diagnosis to clinical management. Exp Mol Med. 2015;47. e132. doi: 10.1038/emm.2014.82. [PubMed: 25613729]. [PubMed Central: PMC4314582].

3. Rickinson AB, Kieff ED. Epstein-Barr virus. In: Knipe DMHP, Griffin DE, Lamb RA, Martin MA, Roizman B, Straus SE, editors. Field virology. 5th ed. Philadelphia: Lippincott Williams \& Wilkins; 2007. p. 2655-700.

4. Odumade OA, Hogquist KA, Balfour HJ. Progress and problems in understanding and managing primary Epstein-Barr virus infections. Clin Microbiol Rev.2011;24(1):193-209. doi:10.1128/CMR.00044-10. [PubMed: 21233512]. [PubMed Central: PMC3021204].

5. Vouloumanou EK, Rafailidis PI, Falagas ME. Current diagnosis and management of infectious mononucleosis. Curr Opin Hematol. 2012;19(1):14-20. doi: 10.1097/MOH.ob013e32834daa08. [PubMed: 22123662].

6. Rickinson A. Epstein-Barr virus. Virus Res. 2002;82(1-2):109-13. doi: 10.1016/s0168-1702(01)00436-1. [PubMed: 11885937].

7. Thorley-Lawson DA, Hawkins JB, Tracy SI, Shapiro M. The pathogenesis of Epstein-Barr virus persistent infection. Curr Opin Virol. 2013;3(3):227-32. doi: 10.1016/j.coviro.2013.04.005. [PubMed: 23683686]. [PubMed Central: PMC3789532].

8. Shannon-Lowe C, Rickinson AB, Bell AI. Epstein-Barr virus-associated lymphomas. Philos Trans R Soc Lond B Biol Sci. 2017;372(1732). doi: 10.1098/rstb.2016.0271. [PubMed: 28893938]. [PubMed Central: PMC5597738].

9. Kim HJ, Ko YH, Kim JE, Lee SS, Lee H, Park G, et al. Epstein-Barr virus-associated lymphoproliferative disorders: Review and update on 2016 WHO classification. J Pathol Transl Med. 2017;51(4):352-8. doi: 10.4132/jptm.2017.03.15. [PubMed: 28592786]. [PubMed Central: PMC5525035].

10. Wolfe LC. Hematologic manifestations of systemic illness. In: Lanzkowsky P, Lipton JM, Fish JD, editors. Lanzkowsky's manual of pediatric hematology and oncology. 6th ed. Elsevier; 2016. p. 17-8.

11. Kuppers R. The biology of Hodgkin's lymphoma. Nat Rev Cancer. 2009;9(1):15-27. doi: 10.1038/nrc2542. [PubMed: 19078975].

12. Kimura H, Kwong YL. EBV viral loads in diagnosis, monitoring, and response assessment. Front Oncol. 2019;9:62. doi: 10.3389/fonc.2019.00062. [PubMed: 30809508]. [PubMed Central: PMC6379266].

13. Hartmann P, Rehwald U, Salzberger B, Franzen C, Sieber M, Wohrmann A, et al. BEACOPP therapeutic regimen for patients with
Hodgkin's disease and HIV infection. Ann Oncol. 2003;14(10):1562-9. doi: 10.1093/annonc/mdg408. [PubMed: 14504059].

14. Enblad G, Sandvej K, Sundstrom C, Pallesen G, Glimelius B. Epstein-Barr virus distribution in Hodgkin's disease in an unselected Swedish population. Acta Oncol. 1999;38(4):425-9. doi: 10.1080/028418699431942. [PubMed:10418708].

15. Glavina-Durdov M, Jakic-Razumovic J, Capkun V, Murray P. Assessment of the prognostic impact of the Epstein-Barr virus-encoded latent membrane protein-1 expression in Hodgkin's disease. Br J Cancer. 2001;84(9):1227-34. doi: 10.1054/bjoc.2001.1774. [PubMed: 11336475]. [PubMed Central: PMC2363896].

16. Chabay PA, Barros MH, Hassan R, De Matteo E, Rey G, Carrico MK, et al. Pediatric Hodgkin lymphoma in 2 South American series: A distinctive epidemiologic pattern and lack of association of Epstein-Barr virus with clinical outcome. J Pediatr Hematol Oncol. 2008;30(4):28591. doi: 10.1097/MPH.ob013e3181647bc3. [PubMed: 18391697].

17. Zhang T, Fu Q, Gao D, Ge L, Sun L, Zhai Q. EBV associated lymphomas in 2008 WHO classification. Pathol Res Pract. 2014;210(2):69-73. doi: 10.1016/j.prp.2013.11.009. [PubMed: 24355441].

18. Brady G, MacArthur GJ, Farrell PJ. Epstein-Barr virus and Burkitt lymphoma. I Clin Pathol. 2007;60(12):1397-402. doi: 10.1136/jcp.2007.047977. [PubMed: 18042696]. [PubMed Central: PMC2095571].

19. Charafeddine K, Hilal L, Bazarbachi A, Salame N, Youssef B. Hyperfractionated radiation therapy in Burkitt's lymphoma: A reconsideration aspect. Hematol Oncol. 2017;35(4):856-60. doi: 10.1002/hon.2294. [PubMed: 27184835].

20. Gloghini A, Dolcetti R, Carbone A. Lymphomas occurring specifically in HIV-infected patients: from pathogenesis to pathology. Semin Cancer Biol. 2013;23(6):457-67. doi: 10.1016/j.semcancer.2013.08.004. [PubMed: 23999127].

21. Kimura H, Kawada J, Ito Y. Epstein-Barr virus-associated lymphoid malignancies: The expanding spectrum of hematopoietic neoplasms. Nagoya J Med Sci. 2013;75(3-4):169-79. [PubMed: 24640173]. [PubMed Central: PMC4345668].

22. Kalisz K, Alessandrino F, Beck R, Smith D, Kikano E, Ramaiya NH, et al. An update on Burkitt lymphoma: A review of pathogenesis and multimodality imaging assessment of disease presentation, treatment response, and recurrence. Insights Imaging. 2019;10(1):56. doi: 10.1186/s13244-019-0733-7. [PubMed: 31115699]. [PubMed Central: PMC6529494].

23. Wood WA, Lee SJ. Malignant hematologic diseases in adolescents and young adults. Blood. 2011;117(22):5803-15. doi: 10.1182/blood-2010-12283093. [PubMed: 21398581].

24. Nicolae A, Pittaluga S, Abdullah S, Steinberg SM, Pham TA, DaviesHill T, et al. EBV-positive large B-cell lymphomas in young patients: A nodal lymphoma with evidence for a tolerogenic immune environment. Blood.2015;126(7):863-72. doi:10.1182/blood-2015-02-630632. [PubMed: 25999451]. [PubMed Central: PMC4536540].

25. Loong F, Chan AC, Ho BC, Chau YP, Lee HY, Cheuk W, et al. Diffuse large B-cell lymphoma associated with chronic inflammation as an incidental finding and new clinical scenarios. Mod Pathol. 2010;23(4):493501. doi: 10.1038/modpathol.2009.168. [PubMed: 20062008].

26. Sanchez-Gonzalez B, Garcia M, Montserrat F, Sanchez M, Angona A, Solano A, et al. Diffuse large B-cell lymphoma associated with chronic inflammation in metallic implant.JClin Oncol.2013;31(10):e148-51. doi: 10.1200/JCO.2012.42.8250. [PubMed: 23401446].

27. Mynarek M, Schober T, Behrends U, Maecker-Kolhoff B. Posttransplant lymphoproliferative disease after pediatric solid organ transplantation. Clin Dev Immunol. 2013;2013:814973. doi: 10.1155/2013/814973. [PubMed: 24174972]. [PubMed Central: PMC3794558].

28. Dharnidharka VR, Webster AC, Martinez OM, Preiksaitis JK, Leblond V, Choquet S. Post-transplant lymphoproliferative disorders. Nat Rev Dis Primers. 2016;2:15088. doi: 10.1038/nrdp.2015.88. [PubMed: 27189056]. 
29. Al-Mansour Z, Nelson BP, Evens AM. Post-transplant lymphoproliferative disease (PTLD): Risk factors, diagnosis, and current treatment strategies. Curr Hematol Malig Rep. 2013;8(3):173-83. doi:10.1007/s11899013-0162-5. [PubMed: 23737188]. [PubMed Central: PMC4831913].

30. Thompson MP, Kurzrock R. Epstein-Barr virus and cancer. Clin Cancer Res. 2004;10(3):803-21. doi: 10.1158/1078-0432.ccr-0670-3. [PubMed: 14871955].

31. Rezk SA, Weiss LM. Epstein-Barr virus-associated lymphoproliferative disorders. Hum Pathol. 2007;38(9):1293-304. doi: 10.1016/j.humpath.2007.05.020. [PubMed: 17707260].

32. Dekate J, Chetty R. Epstein-Barr virus-associated smooth muscle tumor. Arch Pathol Lab Med. 2016;140(7):718-22. doi: 10.5858/arpa.20150120-RS. [PubMed: 27362573].

33. Magg T, Schober T, Walz C, Ley-Zaporozhan J, Facchetti F, Klein C, et al. Epstein-Barr virus(+) smooth muscle tumors as manifestation of primary immunodeficiency disorders. Front Immunol. 2018;9:368. doi: 10.3389/fimmu.2018.00368. [PubMed: 29535735]. [PubMed Central: PMC5835094].

34. McCarthy AJ, Chetty R. Benign smooth muscle tumors (leiomyomas) of deep somatic soft tissue. Sarcoma. 2018;2018:2071394. doi: 10.1155/2018/2071394. [PubMed: 30271265]. [PubMed Central: PMC6151232].

35. Deyrup AT, Lee VK, Hill CE, Cheuk W, Toh HC, Kesavan S, et al Epstein-Barr virus-associated smooth muscle tumors are distinctive mesenchymal tumors reflecting multiple infection events: A clinicopathologic and molecular analysis of 29 tumors from 19 patients. Am J Surg Pathol. 2006;30(1):75-82. doi: 10.1097/01.pas.0000178088.69394.7b. [PubMed: 16330945].

36. Radu O, Pantanowitz L. Kaposi sarcoma. Arch Pathol Lab Med. 2013;137(2):289-94. doi: 10.5858/arpa.2012-0101-RS. [PubMed: 23368874].

37. Jenson HB, Leach CT, McClain KL, Joshi VV, Pollock BH, Parmley RT, et al. Benign and malignant smooth muscle tumors containing EpsteinBarr virus in children with AIDS. Leuk Lymphoma. 1997;27(3-4):303-14. doi: 10.3109/10428199709059684. [PubMed: 9402327].

38. Jenson HB, Montalvo EA, McClain KL, Ench Y, Heard P, Christy BA, et al. Characterization of natural Epstein-Barr virus infection and replication in smooth muscle cells from a leiomyosarcoma. J Med Virol. 1999;57(1):36-46. [PubMed: 9890420].

39. Liu Y, Chintalapati S, Dietz R, Raza AS, Wang J, Raza AS. EBV-associated hepatic smooth muscle tumor of uncertain biologic behavior after heart transplantation in a pediatric patient: Case report. J Gastrointest Oncol. 2017;8(1):E21-5. doi: 10.21037/jgo.2016.12.05. [PubMed: 28280632]. [PubMed Central: PMC5334067].

40. Moody CA, Scott RS, Amirghahari N, Nathan CO, Young LS, Dawson CW, et al. Modulation of the cell growth regulator mTOR by Epstein-Barr virus-encoded LMP2A. J Virol. 2005;79(9):5499-506. doi: 10.1128/JVI.79.9.5499-5506.2005. [PubMed: 15827164]. [PubMed Central: PMC1082717].

41. McClain KL, Leach CT, Jenson HB, Joshi VV, Pollock BH, Parmley RT, et al. Association of Epstein-Barr virus with leiomyosarcomas in young people with AIDS. N Engl J Med. 1995;332(1):12-8. doi: 10.1056/NEJM199501053320103. [PubMed: 7990860].

42. Hussein K, Maecker-Kolhoff B, Donnerstag F, Laenger F, Kreipe H, Jonigk D. Epstein-Barr virus-associated smooth muscle tumours after transplantation, infection with human immunodeficiency virus and congenital immunodeficiency syndromes. Pathobiology. 2013;80(6):297-301. doi: 10.1159/000351326. [PubMed: 24013109].

43. Hussein K, Rath B, Ludewig B, Kreipe H, Jonigk D. Clinico-pathological characteristics of different types of immunodeficiency-associated smooth muscle tumours. Eur J Cancer. 2014;50(14):2417-24. doi: 10.1016/j.ejca.2014.06.006. [PubMed: 25027306].

44. Jossen J, Chu J, Hotchkiss H, Wistinghausen B, Iyer K, Magid M, et al. Epstein-Barr virus-associated smooth muscle tumors in children following solid organ transplantation: a review. Pediatr Transplant. 2015;19(2):235-43. doi:10.1111/petr.12426. [PubMed: 25572657].
45. Jonigk D, Laenger F, Maegel L, Izykowski N, Rische J, Tiede C, et al. Molecular and clinicopathological analysis of Epstein-Barr virus-associated posttransplant smooth muscle tumors. Am J Transplant.2012;12(7):1908-17. doi:10.1111/j.1600-6143.2012.04011.x. [PubMed: 22420456].

46. Young LS, Dawson CW. Epstein-Barr virus and nasopharyngeal carcinoma. Chin J Cancer. 2014;33(12):581-90. doi: 10.5732/cjc.014.10197. [PubMed: 25418193]. [PubMed Central: PMC4308653].

47. Shibata D, Tokunaga M, Uemura Y, Sato E, Tanaka S, Weiss LM. Association of Epstein-Barr virus with undifferentiated gastric carcinomas with intense lymphoid infiltration. Lymphoepithelioma-like carcinoma. Am J Pathol. 1991;139(3):469-74. [PubMed: 1653517]. [PubMed Central: PMC1886210].

48. Niedobitek G. Epstein-Barr virus infection in the pathogenesis of nasopharyngeal carcinoma. Mol Pathol. 2000;53(5):248-54 doi: 10.1136/mp.53.5.248. [PubMed: 11091848]. [PubMed Central: PMC1186977].

49. Xu Y, Shi Y, Yuan Q, Liu X, Yan B, Chen L, et al. Epstein-Barr virus encoded LMP1 regulates cyclin D1 promoter activity by nuclear EGFR and STAT3 in CNE1 cells. J Exp Clin Cancer Res. 2013;32:90. doi: 10.1186/17569966-32-90. [PubMed: 24499623]. [PubMed Central: PMC3843577].

50. Valentine R, Dawson CW, Hu C, Shah KM, Owen TJ, Date KL, et al Epstein-Barr virus-encoded EBNA1 inhibits the canonical NF-kappaB pathway in carcinoma cells by inhibiting IKK phosphorylation. Mol Cancer. 2010;9:1. doi: 10.1186/1476-4598-9-1. [PubMed: 20051109]. [PubMed Central: PMC2818691].

51. Cao Y. EBV based cancer prevention and therapy in nasopharyngeal carcinoma. NPJ Precis Oncol. 2017;1(1):10. doi: 10.1038/s41698-017-0018x. [PubMed: 29872698]. [PubMed Central: PMC5871899].

52. Zheng XH, Lu LX, Li XZ, Jia WH. Quantification of Epstein-Barr virus DNA load in nasopharyngeal brushing samples in the diagnosis of nasopharyngeal carcinoma in southern China. Cancer Sci. 2015;106(9):1196-201. doi: 10.1111/cas.12718. [PubMed: 26082292] [PubMed Central: PMC4582989].

53. Penas-Prado M, Diaz-Guzman J, Jimenez-Huerta I, Juntas-Morales R, Villarejo-Galende A, Diez-Torres I. [Gradenigo syndrome as the form of presentation of nasopharyngeal carcinoma]. Rev Neurol. 2001;32(7):638-40. Spanish. [PubMed:11391492].

54. Domaa AM, Gad HA. The clinical manifestations of nasopharyngeal cancer in Libya-a comparative study. Middle East J Appl Sci. 2011;1(1):14.

55. Henter JI, Horne A, Arico M, Egeler RM, Filipovich AH, Imashuku S, et al. HLH-2004: Diagnostic and therapeutic guidelines for hemophagocytic lymphohistiocytosis. Pediatr Blood Cancer. 2007;48(2):124-31. doi: 10.1002/pbc.21039. [PubMed:16937360].

56. Fox CP, Shannon-Lowe C, Gothard P, Kishore B, Neilson J, O'Connor $\mathrm{N}$, et al. Epstein-Barr virus-associated hemophagocytic lymphohistiocytosis in adults characterized by high viral genome load within circulating natural killer cells. Clin Infect Dis. 2010;51(1):66-9. doi: 10.1086/653424. [PubMed: 20504238].

57. Xu XJ, Wang HS, Ju XL, Xiao PF, Xiao Y, Xue HM, et al. Clinical presentation and outcome of pediatric patients with hemophagocytic lymphohistiocytosis in China: A retrospective multicenter study. Pediatr Blood Cancer. 2017;64(4). doi: 10.1002/pbc.26264. [PubMed: 27781387].

58. Marsh RA. Epstein-Barr virus and hemophagocytic lymphohistiocytosis. Front Immunol. 2017;8:1902. doi: 10.3389/fimmu.2017.01902. [PubMed: 29358936]. [PubMed Central: PMC5766650].

59. Jenson HB. Acute complications of Epstein-Barr virus infectious mononucleosis. Curr Opin Pediatr. 2000;12(3):263-8. doi: 10.1097/00008480-200006000-00016. [PubMed: 10836164].

60. Ishii E. Hemophagocytic lymphohistiocytosis in children: Pathogenesis and treatment. Front Pediatr. 2016;4:47. doi: 10.3389/fped.2016.00047. [PubMed: 27242976]. [PubMed Central: PMC4865497].

61. Hashemi-Sadraei N, Vejpongsa P, Baljevic M, Chen L, Idowu M. Epstein- 
barr virus-related hemophagocytic lymphohistiocytosis: Hematologic emergency in the critical care setting. Case Rep Hematol. 2015;2015:491567. doi: 10.1155/2015/491567. [PubMed: 25755898]. [PubMed Central: PMC4338404].

62. Israel BF, Kenney SC. Virally targeted therapies for EBVassociated malignancies. Oncogene. 2003;22(33):5122-30. doi: 10.1038/sj.onc.1206548. [PubMed: 12910249].

63. Heslop HE. Biology and treatment of Epstein-Barr virus-associated non-Hodgkin lymphomas. Hematology Am Soc Hematol Educ Program. 2005:260-6. doi: 10.1182/asheducation-2005.1.260. [PubMed: 16304390].

64. Chan AT, Tao Q, Robertson KD, Flinn IW, Mann RB, Klencke B, et al. Azacitidine induces demethylation of the Epstein-Barr virus genome in tumors. J Clin Oncol. 2004;22(8):1373-81. doi: 10.1200/JCO.2004.04.185. [PubMed:15007085].

65. Feng WH, Hong G, Delecluse HJ, Kenney SC. Lytic induction therapy for Epstein-Barr virus-positive B-cell lymphomas. J Virol. 2004;78(4):1893-902. doi: 10.1128/jvi.78.4.1893-1902.2004. [PubMed: 14747554]. [PubMed Central: PMC369434].

66. Oertel SH, Riess H. Antiviral treatment of Epstein-Barr virusassociated lymphoproliferations. Recent Results Cancer Res. 2002;159:89-95. doi: 10.1007/978-3-642-56352-2_11. [PubMed 11785848].

67. Neyts J, Sadler R, De Clercq E, Raab-Traub N, Pagano JS The antiviral agent cidofovir [(S)-1-(3-hydroxy-2-phosphonylmethoxypropyl)cytosine] has pronounced activity against nasopharyngeal carcinoma grown in nude mice. Cancer Res. 1998;58(3):384-8. [PubMed: 9458076].

68. Hanel M, Fiedler F, Thorns C. Anti-CD20 monoclonal antibody (Rit- uximab) and Cidofovir as successful treatment of an EBV-associated lymphoma with CNS involvement. Onkologie. 2001;24(5):491-4. doi: 10.1159/000055132. [PubMed: 11694778].

69. Abdulkarim B, Bourhis J. Antiviral approaches for cancers related to Epstein-Barr virus and human papillomavirus. Lancet Oncol. 2001;2(10):622-30. doi: 10.1016/S1470-2045(01)00520-4. [PubMed: 11902553].

70. Gottschalk S, Heslop HE, Roon CM. Treatment of Epstein-Barr virus-associated malignancies with specific T cells. Adv Cancer Res. 2002;84:175-201. doi: 10.1016/s0065-230x(02)84006-4. [PubMed: 11883527].

71. Lucas KG, Salzman D, Garcia A, Sun Q. Adoptive immunotherapy with allogeneic Epstein-Barr virus (EBV)-specific cytotoxic Tlymphocytes for recurrent, EBV-positive Hodgkin disease. Cancer. 2004;100(9):1892-901. doi:10.1002/cncr.20188. [PubMed: 15112270].

72. Haddad E, Paczesny S, Leblond V, Seigneurin JM, Stern M, Achkar A, et al. Treatment of B-lymphoproliferative disorder with a monoclonal anti-interleukin- 6 antibody in 12 patients: A multicenter phase 1-2 clinical trial. Blood. 2001;97(6):1590-7. doi: 10.1182/blood.v97.6.1590. [PubMed: 11238096].

73. Cohen JI. Vaccine development for Epstein-Barr virus. Adv Exp Med Biol. 2018;1045:477-93. doi: 10.1007/978-981-10-7230-7_22. [PubMed: 29896681]. [PubMed Central: PMC6328312].

74. Nijland ML, Kersten MJ, Pals ST, Bemelman FJ, Ten Berge IJ. EpsteinBarr virus-positive posttransplant lymphoproliferative disease after solid organ transplantation: Pathogenesis, clinical manifestations, diagnosis, and management. Transplant Direct. 2016;2(1). e48. doi: 10.1097/TXD.0000000000000557. [PubMed: 27500242]. [PubMed Central: PMC4946499]. 